\title{
REVIEWS
}

\section{Benefits and Harms of Long-term Opioid Dose Reduction or Discontinuation in Patients with Chronic Pain: a Rapid Review}

\author{
Katherine Mackey, MD, MPP, Johanna Anderson, MPH, Donald Bourne, MPH, \\ Emilie Chen, BS, and Kim Peterson, MS
}

Evidence Synthesis Program (ESP) Coordinating Center, VA Portland Health Care System, R\&D 713710 SW U.S. Veterans Hospital Road, Portland, OR, USA.

BACKGROUND: Many clinicians are reevaluating the use of long-term opioid therapy (LTOT) for chronic pain in response to the opioid crisis and calls from organizations including the Centers for Disease Control \& Prevention to limit prescribing of high-dose opioids. However, this practice change is occurring largely in the absence of data regarding patient outcomes. A 2017 systematic review found inconclusive evidence on the impact of LTOT dose reduction and discontinuation on pain severity and function, quality of life, withdrawal symptoms, substance abuse, and adverse effects. This rapid systematic review provides an updated evidence synthesis of patient outcomes following LTOT dose reduction including serious harms such as overdose and suicide.

METHODS: We systematically searched numerous bibliographic databases from January 2017 (the end search date of the 2017 systematic review) through May 2020. One reviewer used prespecified criteria to assess articles for inclusion, evaluate study quality, abstract data, and grade strength of evidence, with a second reviewer checking.

RESULTS: We included 49 studies-1 systematic review, 34 studies included in that systematic review, and 14 new studies. We prioritized evidence synthesis of 19 studies with the most applicability to the Veteran population and outpatient settings. Among these studies, improvements in mean pain scores were common among patients tapering opioids while participating in intensive multimodal pain interventions and mostly unchanged with less intensive or nonspecific co-interventions. Our confidence in these findings is low due to methodological limitations of the studies. Observational data suggests that serious harms such as opioid overdose and suicidal ideation can occur following opioid dose reduction or discontinuation, but the incidence of these harms at the population level is unknown.

$\overline{\text { Prior Presentations This work is based on a full report that is available }}$ on the ESP website at https://www.hsrd.research.va.gov/publications/ esp/reports.cfm. The report was presented during an HSR\&D Cyberseminar on August 27, 2019.

Protocol Registration PROSPERO; CRD42019129110

Electronic supplementary material The online version of this article (https://doi.org/10.1007/s11606-020-06253-8) contains supplementary material, which is available to authorized users.

Received February 7, 2020

Accepted September 17, 2020

Published online November 3, 2020
DISCUSSION: The net balance of benefits and harms of LTOT dose reduction for patients with chronic pain is unclear. Clinicians should closely monitor patients during the tapering process given the potential for harm.

KEY WORDS: chronic pain; opioids; tapering.

J Gen Intern Med 35(Suppl 3):S935-S44

DOI: $10.1007 / \mathrm{s} 11606-020-06253-8$

(c) Society of General Internal Medicine (This is a U.S. government work and not under copyright protection in the U.S.; foreign copyright protection may apply) 2020

\section{BACKGROUND}

In response to the evolving crisis of opioid-related morbidity, mortality, and misuse fueled initially by prescription opioids, ${ }^{1}$ many clinicians have changed their approach to long-term opioid therapy (LTOT) for chronic pain by prescribing lower opioids doses and fewer opioids overall. ${ }^{2}$ Publication of the 2016 Centers for Disease Control \& Prevention (CDC) Guideline for Prescribing Opioids for Chronic Pain accelerated this change by highlighting opioid risks and a relative lack of evidence to support LTOT benefits. The CDC guideline urges clinicians to avoid or carefully justify prescribing opioid doses $>90 \mathrm{mg}$ morphine equivalent daily dose (MEDD) and involve patients in shared decision-making regarding dose reductions if they are already prescribed doses $>90 \mathrm{mg}$ MEDD. ${ }^{1}$ Similar approaches are recommended by the Veterans Affairs/ Department of Defense (VA/DoD) and other groups. ${ }^{3-6}$

Although the association between high-dose opioid prescribing and increased risk of overdose is not in question, ${ }^{7}$ opioid dose reduction and discontinuation (also referred to as tapering when doses are reduced gradually) for patients with chronic pain on LTOT is occurring largely in the absence of data regarding patient outcomes. A good-quality 2017 systematic review of 40 mostly uncontrolled observational studies by Frank et al. found inconclusive evidence on the impact of LTOT tapers on pain severity, pain-related function, quality of life, withdrawal symptoms, substance abuse, and adverse effects. ${ }^{8}$ Meanwhile, as highlighted by the US Food and Drug Administration, anecdotal evidence is accumulating that patients may be at risk for serious harm when opioids are reduced too rapidly and without adequate 
provider communication or follow-up. ${ }^{9}$ The need to fill the evidence gap regarding patient outcomes after tapers is urgent amid growing concern that some clinicians, health systems, and payers have misapplied the guidelines, imposing opioid tapers or dosing thresholds on patients. In a 2019 editorial titled "No Shortcuts to Safer Opioid Prescribing," authors of the CDC guideline acknowledged these concerns, clarified the intent of the guidelines, and criticized inflexible prescribing limits and abrupt opioid discontinuation. ${ }^{10}$

This manuscript summarizes findings of a rapid review ${ }^{11}$ and updated literature search conducted by the Department of Veterans Affairs Evidence Synthesis Program (VA ESP) on patient outcomes following opioid dose reduction and discontinuation in order to inform an August 2019 VA Health Services Research \& Development (HSR\&D) conference on opioid safety. Although we prioritized evidence synthesis of studies most applicable to Veterans Health Administration (VHA) populations and settings, this review is relevant to all clinicians caring for patients with chronic pain on LTOT. To the best of our knowledge, this is the most current review of opioid tapering outcomes and the most comprehensive in terms of evaluating harms.

\section{METHODS}

Our review was guided and reported by current standard systematic review methods and guidelines. ${ }^{12,13}$ The complete description of our methods can be found on the PROSPERO international prospective register of systematic reviews (http:// www.crd.york.ac.uk/PROSPERO/; registration number CRD42019129110), and in our full report. ${ }^{11}$ To accommodate a condensed timeline, we used sequential instead of independent dual review processes to minimize bias and error and prioritized evidence synthesis of studies most relevant to our population of interest (VHA patients).

\section{Search Strategy}

We searched MEDLINE® (Ovid), PsychInfo, Cochrane Register of Controlled Trials, Cochrane Database of Systematic Reviews, and Embase from January 1, 2017 (the end search date of the Frank et al. systematic review) through May 6, 2020, using terms for opioids, dose reduction, discontinuation, and pain (see Appendix A for full search strategies). Additional citations were identified from hand-searching reference lists and consultation with content experts. We limited the search to articles involving human subjects available in the English language.

\section{Study Selection}

Study selection was based on the eligibility criteria described in Figure 1.

\section{Data Abstraction and Quality Assessment}

We abstracted data from all included studies on study design, patient characteristics, opioid use, interventions, and outcomes (see Appendix B for data abstraction results). For studies included in the systematic review by Frank et al., we relied on risk of bias ratings and abstracted data from that review (abstracting data on additional outcomes as needed). For subsequently published controlled studies, we used the Cochrane Risk of Bias Tools to rate the internal validity (see Appendix C for full quality assessment). ${ }^{14}$ All data abstraction and internal validity ratings were first completed by one reviewer and then checked by another. All disagreements were resolved by consensus or assessment by a third reviewer.

\section{Strength of Evidence and Data Synthesis}

We used the GRADE framework ${ }^{15}$ to evaluate the quality of the body of evidence. This framework considers study limitations (risk of bias), consistency of results, directness, and precision of the evidence. Ratings typically range from high to very low, reflecting our confidence that the evidence reflects the true effect. For this review, we applied the following general algorithm: evidence comprised of multiple observational studies with consistent findings received a rating of "low," whereas the same type of evidence with few studies and/or indirectness and inconsistency was downgraded to "very low." We synthesized evidence qualitatively and did not perform quantitative synthesis due to limited data or heterogeneity.

\section{RESULTS}

The literature flow diagram (Fig. 2) summarizes the results of the search and study selection processes. Among 3,155 potentially relevant citations, we included 49 studies -1 systematic review (Frank et al.), ${ }^{8} 34$ studies included in that systematic review, ${ }^{16-49}$ and 14 new studies identified in our literature search. ${ }^{50-63}$ A total of 40,245 patients are included in the 14 new studies.

We prioritized evidence synthesis of: 1) studies conducted in a VHA setting or other outpatient settings; 2) studies that addressed serious harms such as overdose and suicide; and 3) studies that included enough detail regarding patient and tapering characteristics to evaluate the applicability of findings to VHA populations and settings. Nineteen studies (Table 1) (2 RCTs, ${ }^{18,}{ }^{50} 6$ controlled observational studies, ${ }^{54,56,60-63}$

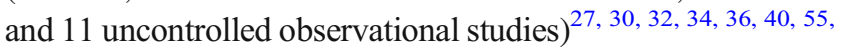
57-59, 65 met these criteria, which we refer to as "prioritized studies." The remaining studies either had low applicability to VHA or outpatient settings or included patients or interventions that were not well-described. Also, unless they otherwise met our prioritization criteria, we do not discuss poor-quality studies included in Frank et al. in detail (see Table 1 for patient and taper characteristics of prioritized studies). Data tables for all included studies are available in online Appendix A and a list of all included and excluded studies are in our report's supplemental materials. ${ }^{11}$ Table 2 provides an overview of results. Findings for specific patient outcomes are discussed below. 


\begin{tabular}{|c|c|}
\hline Population & $\begin{array}{l}\text { Adults prescribed long-term opioids ( } \geq 3 \text { months) for chronic pain (excluding patients } \\
\text { receiving palliative care, treatment for cancer-related pain, or undergoing surgery) } \\
\text { including patients with co-morbid chronic pain and substance use disorder (excluding } \\
\text { patients with substance use disorder only) }\end{array}$ \\
\hline Intervention & $\begin{array}{l}\text { Dose reduction or discontinuation (excluding studies of chronic pain interventions not } \\
\text { explicitly designed to lower opioid doses) }\end{array}$ \\
\hline Comparator & Any \\
\hline Outcomes & $\begin{array}{l}\text { Pain severity, pain-related function, quality of life, opioid withdrawal symptoms, } \\
\text { patient satisfaction, healthcare utilization, retention in primary care, change in } \\
\text { depression and anxiety symptoms, new or increased substance use, opioid overdose, } \\
\text { suicidal ideation and suicidal self-directed violence (EXCLUDE studies that only } \\
\text { report MEDD changes without other patient outcomes) }\end{array}$ \\
\hline Timing & Any study follow-up durations \\
\hline Setting & Any, but may prioritize to accommodate timeline using a best-evidence approach \\
\hline Study design & Any, but may prioritize to accommodate timeline using a best-evidence approach \\
\hline
\end{tabular}

Figure 1 Eligibility criteria.

\section{Pain and Pain-Related Function}

Studies reported mean changes in pain severity and intensity scores (as measured by tools such as the pain numerical rating scale, multidimensional pain inventory, and brief pain inventory). Most studies did not define clinically important changes on these scales or state whether opioid dose reduction resulted in severe pain requiring a change in management with a few exceptions. ${ }^{36,63}$ Seven observational studies of opioid tapering in the context of intensive 3-4-week multimodal pain management programs requiring full-day participation Monday-Friday showed improvements in pain severity and intensity scores. $^{27,32,34,36,40,63,65}$ Among studies reporting mean pain scores at baseline and endpoint, improvements were greatest $(19-47 \%)$ in studies of patients on higher baseline MEDD (99-177 mg) $27,32,36,46$ and more modest (8-10\%) among studies of patients with lower baseline MEDD (47-61

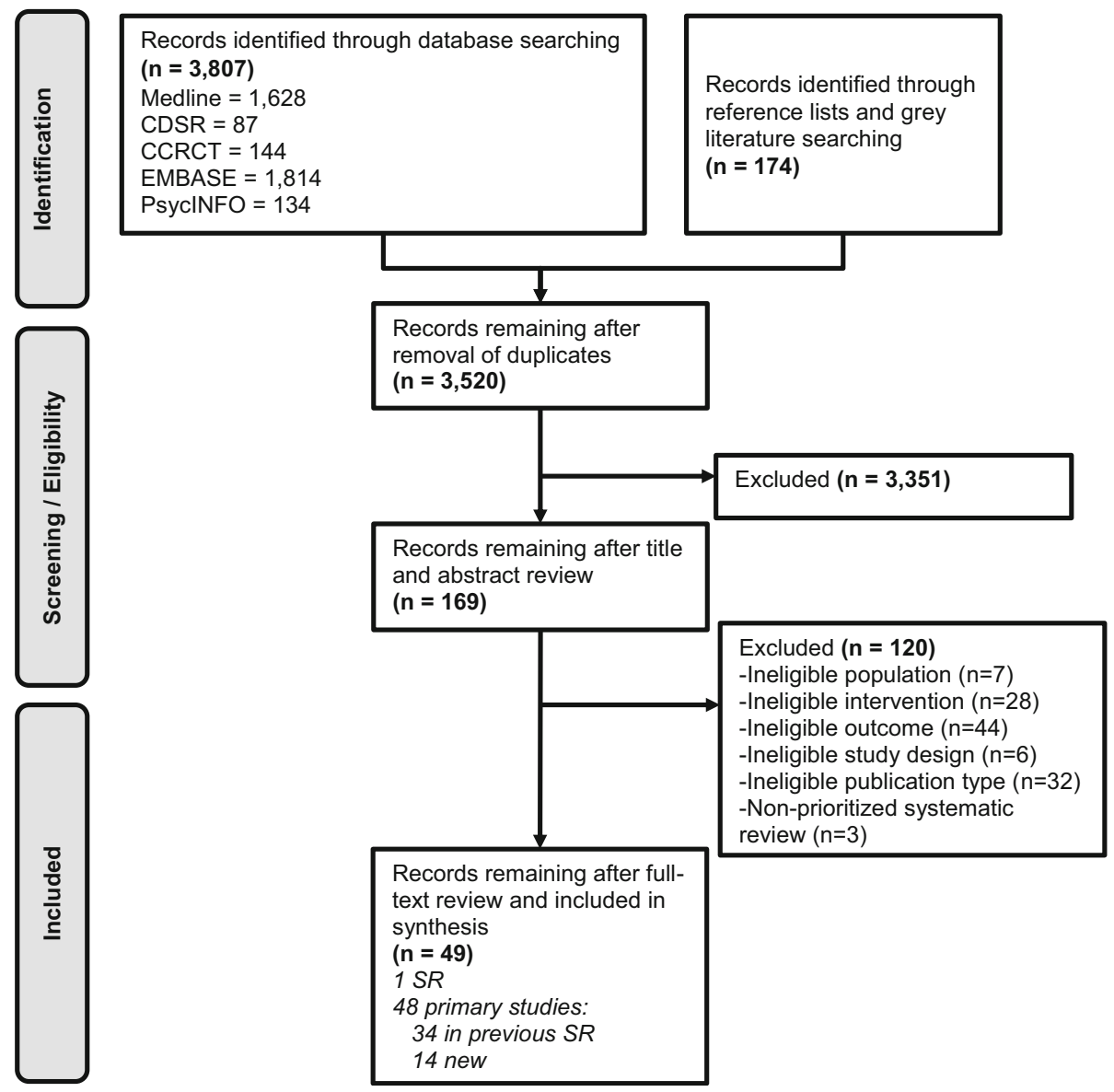

Figure 2 Literature flow. 


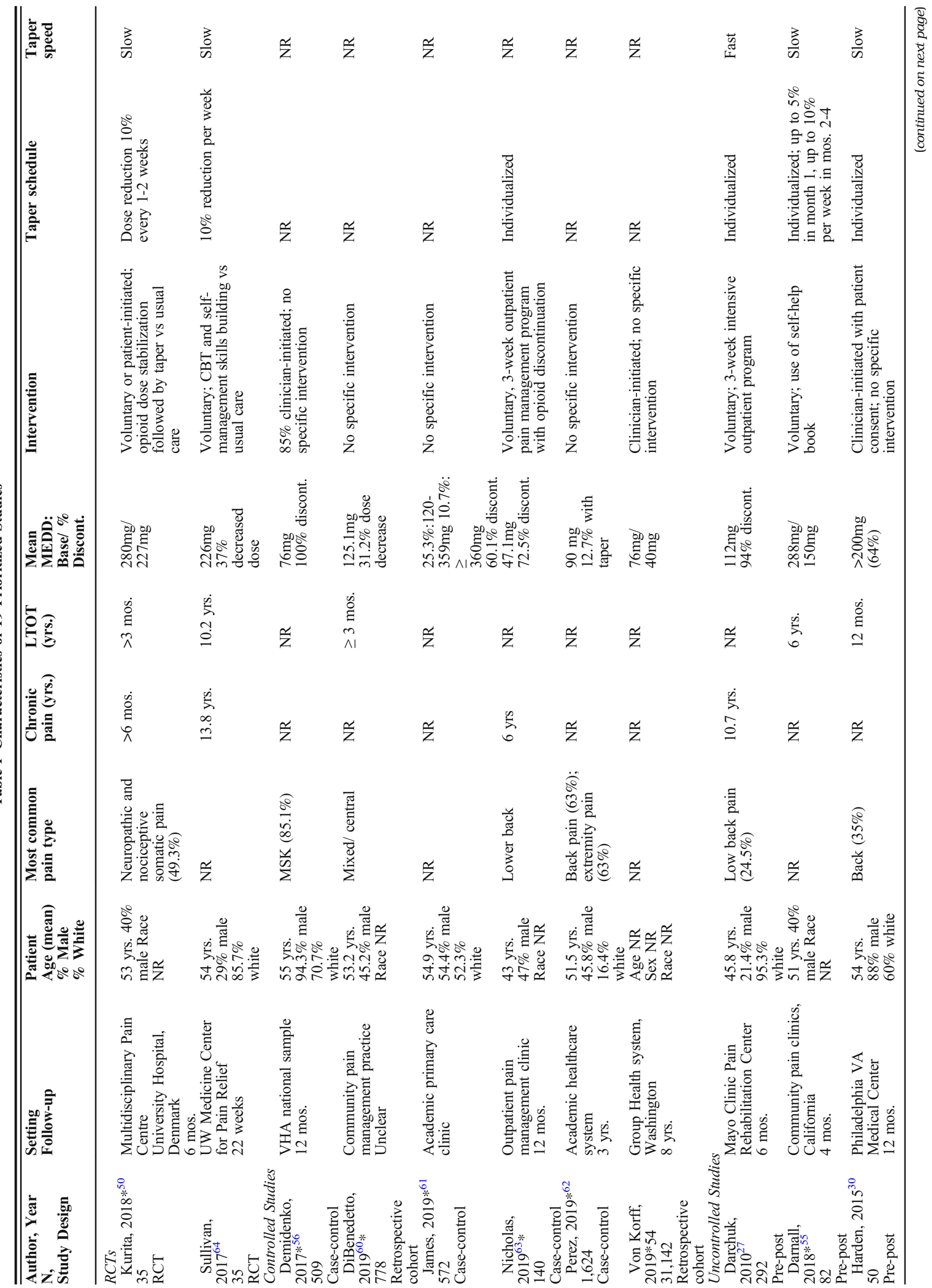




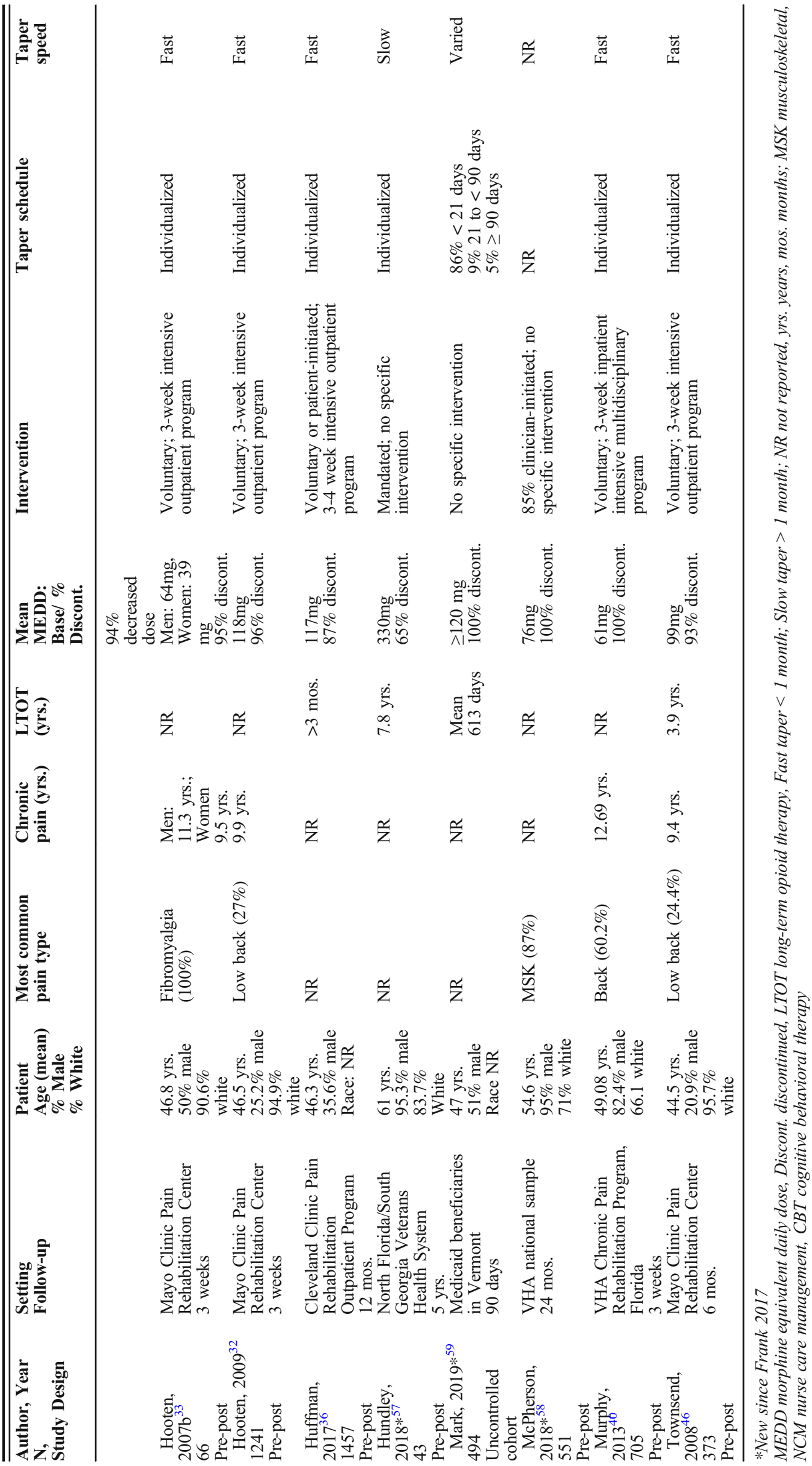


Table 2 Outcomes of 19 Prioritized Studies ${ }^{18,27,30,32,34,36,40,46,50,54-59,61,63}$

\begin{tabular}{|c|c|c|c|c|c|c|c|c|c|}
\hline \multirow[b]{2}{*}{ Author, Year } & \multicolumn{6}{|c|}{ Patient Outcomes } & \multicolumn{3}{|c|}{ Adverse Events } \\
\hline & $\begin{array}{c}\text { Pain } \\
\text { Severity }\end{array}$ & $\begin{array}{l}\text { Pain-related } \\
\text { Function }\end{array}$ & $\begin{array}{l}\text { Quality of } \\
\text { Life }\end{array}$ & $\begin{array}{c}\text { Patient } \\
\text { Satisfaction }\end{array}$ & $\begin{array}{l}\text { Healthcare } \\
\text { Utilization } \\
\text { or } \\
\text { Retention }\end{array}$ & $\begin{array}{l}\text { Depression } \\
\text { or Anxiety }\end{array}$ & $\begin{array}{l}\text { Withdrawal } \\
\text { Symptoms }\end{array}$ & $\begin{array}{c}\text { SUD or } \\
\text { Opioid } \\
\text { Overdose }\end{array}$ & $\begin{array}{c}\text { Suicidal } \\
\text { Ideation or } \\
\text { SSV }\end{array}$ \\
\hline \multicolumn{10}{|c|}{ High Intensity Co-interventions (e.g. multimodal pain management programs with daily attendance over several weeks) } \\
\hline Darchuk, $2010_{18}$ & $\checkmark$ & $\checkmark$ & & & & $\checkmark$ & & & \\
\hline Hooten, 2007b27 & $\checkmark$ & $\checkmark$ & $\checkmark$ & & & $\checkmark$ & & & \\
\hline Hooten, 200930 & $\checkmark$ & & & & & & & & \\
\hline Huffman, 201732 & $\checkmark$ & $\checkmark$ & & & & $\checkmark$ & & & \\
\hline Murphy, 201334 & $\checkmark$ & $\checkmark$ & $\checkmark$ & $\checkmark$ & & & & & \\
\hline Nicholas, $201936^{*}$ & $\checkmark$ & $\checkmark$ & & & & & & & \\
\hline Townsend, 200840 & $\checkmark$ & $\checkmark$ & $\checkmark$ & & & $\checkmark$ & & & \\
\hline \multicolumn{10}{|c|}{ Moderate Intensity Co-interventions (e.g. outpatient pain management combined with enhanced psychosocial supports) } \\
\hline Kurita, $2018^{*} 46$ & $=$ & & $\checkmark$ & & & $=$ & $x$ & & \\
\hline Sullivan, $2017_{50}$ & $\checkmark$ & $\checkmark$ & & & & & & & \\
\hline \multicolumn{10}{|c|}{ Low Intensity Co-Intervention (e.g. use of a self-help book) } \\
\hline Darnall, $2018^{*} 54$ & $=$ & $=$ & & & & & & & \\
\hline \multicolumn{10}{|c|}{ Undefined Co-intervention or Usual Care } \\
\hline Demidenko, 2017*55 & & & & & & & & & $x$ \\
\hline DiBenedetto, 2019* & $=$ & $=$ & & & & & & & \\
\hline Harden, 201556 & $\checkmark$ & & & & & & & & \\
\hline Hundley, $2018^{* 57}$ & & & & & $=$ & & & $x$ & $x$ \\
\hline James, $2019{ }^{*} 58$ & & & & & $x$ & & & $x$ & \\
\hline Mark, $201{ }^{*}{ }_{59}$ & & & & & $x$ & & & $x$ & \\
\hline McPherson, 2018*61 & $=$ & & & & & & & & \\
\hline Perez, 2019* & & & & & $x$ & & & & \\
\hline Von Korff, 2019*63 & & & & & & & & $x$ & \\
\hline $\begin{array}{l}\text { Overall Evidence } \\
\text { Quality }\end{array}$ & & ow & & Very L & ow & & & Very Low & \\
\hline
\end{tabular}

*New since Frank 2017; SUD substance use disorder, SSV suicidal self-directed violence; blank cells no data reported; no studies reported on opioidrelated side effect outcomes

$\checkmark$ symptoms improved; $=$ No change in symptoms; $\mathbf{x}$ Reported with unclear effect or no comparator

$\mathrm{mg}){ }^{63,}{ }^{66}$ Although these results are encouraging, studies of intensive multimodal pain management programs have limited applicability overall given that many patients lack access to or means to participate in such programs.

The best evidence of the impact of opioid tapering on pain severity with a moderate co-intervention is an RCT in which patients with chronic pain who wanted to taper opioids were randomized to usual care versus a tapering support intervention that included psychiatric consultation and 18 weekly meetings with a physician assistant to improve selfmanagement skills. In both groups, patients had lower pain severity ratings at 22 weeks and patients in the intervention group also had improvements in pain interference and pain self-efficacy. ${ }^{18}$ Another RCT of a moderate-intensity intervention relied on voluntary opioid tapering and had a high dropout rate, prompting the study authors to deem the intervention unsuccessful. ${ }^{50}$ The least intensive intervention was an observational study of 51 patients in a community pain clinic with high baseline MEDD $(288 \mathrm{mg})$ who voluntarily participated in a slow individualized taper with the use of a self-help book and had mean improvements in pain scores of $10 \%$. In another observational study of tapering, 50 VHA patients with high baseline MEDD (64\% > $200 \mathrm{mg}$ ) who tapered opioids with usual care had less pain $(40 \%)$ or unchanged pain $(28 \%)$ at $6-$ 12 months. $^{30}$

Importantly, patients participated voluntarily in tapering interventions described above. Only 1 study that evaluated pain scores at baseline and endpoint provides information regarding patient outcomes after clinician-initiated or mandated tapers. In a retrospective study of 551 VHA patients with baseline MEDD $76 \mathrm{mg}$ in which the majority (85\%) underwent clinician-initiated tapers, pain scores improved by $3.8 \%{ }^{58} \mathrm{~A}$ limitation of this study is that it does not include patients who discontinued VA care or continued VA care but received pain management elsewhere.

Similar trends were noted for mean changes in pain-related function following opioid tapers. The most improvement was observed in a group of 1457 patients (baseline MEDD 117 $\mathrm{mg}$ ) who participated in an intensive outpatient multimodal pain management program at the Cleveland Clinic. ${ }^{36}$ In this study, the mean score on the pain disability index (PDI) decreased from 42.95 at baseline to 18.29 at discharge ($57.4 \%$ ) and was 23.7 after 6-12 months of follow-up ($44.8 \%) .{ }^{36}$ Similarly, in a VHA study of an intensive intervention in which 705 veterans (baseline MEDD $61 \mathrm{mg}$ ) voluntarily participated in a 3 -week interdisciplinary pain program 
incorporating opioid cessation, scores on the VA Pain Outcomes Questionnaire-interference in Activities of Daily Living (POQ-ADL) decreased from 16 at baseline to 13 at 3-week discharge $(-18.8 \%){ }^{40}$ The smallest (and statistically nonsignificant) change came following the least intense intervention, in which an individualized taper was accompanied by a selfhelp book. ${ }^{55}$ While it is encouraging that mean pain scores and functional measures improved or did not significantly change for most patients who reduced or discontinued opioids, these types of outcome assessments may be of limited utility as they do not necessarily correlate with meaningful changes from the patient perspective.

We have low confidence in these findings (low quality per GRADE). The body of evidence has several limitations including a high proportion of uncontrolled observational studies (which introduce the potential for unmeasured confounders), unclear fidelity to interventions, and inadequate reporting of missing data and handling of missing data. Despite these limitations, within our subset of studies, findings regarding pain and pain-related function were consistent.

\section{Serious Harms: Substance Use, Opioid Overdose, and Suicide}

Evidence regarding the impact of opioid dose reduction and discontinuation on substance use, opioid overdose, and suicide is unclear and highlights the challenges of studying complex linkages among the problems of chronic pain, opioid dependence, opioid use disorder, suicidal ideation, and co-morbid mental health disorders. A 2019 retrospective study of Medicaid claims data in Vermont found that among a cohort of 694 Medicaid recipients who had a high prevalence of substance use disorders (60\%) on $\geq 120 \mathrm{mg}$ MEDD, almost half (49\%) of 494 patients who discontinued opioids between 2013 and 2017 subsequently had an ED visit or hospitalization due to opioid poisoning or substance use disorder. ${ }^{59}$ In this study, opioids were most often discontinued without a gradual taper (median length of time to discontinuation was 1 day) and $<1 \%$ of patients were prescribed medication to treat substance use disorders. This study does not describe the circumstances regarding opioid discontinuation or exclude the potential for reverse causality (i.e., a diagnosis of substance use disorder was the reason prescription opioids were discontinued) but highlights a real-world pattern of abrupt opioid discontinuation as well as undertreatment of substance use disorders.

We identified 3 observational studies that examined overdose as an outcome of opioid dose reduction. ${ }^{54,57,61}$ Because opioid overdoses are rare events, larger population-level studies are more informative than small studies. The only large study of opioid overdose is a retrospective study of overdose rates following different phases of an opioid risk reduction initiative among patients in Washington's Group Health practice (intervention group) compared to patients in Group Health's contracted community clinics (control group) ${ }^{54}$ Both groups were subject to a change in Washington State's opioid prescribing guidelines recommending against doses $\geq 120 \mathrm{mg}$ MEDD, but providers in the intervention group also received "feedback and supervisory guidance by medical directors". The within-group analysis demonstrated a significant decrease in overdose rates (relative annual change $0.83,95 \% \mathrm{CI} 0.70$ to 0.99 ), but the between-groups analysis did not. Overall, the results of this study provide inconsistent support that reducing opioid doses leads to lower overdose rates.

The other 2 studies of overdose after opioid discontinuation are smaller. In a retrospective study of 572 patients in a primary care clinic on LTOT during 2010-2015, 17 (4.9\%) patients who discontinued opioids died of an overdose and 4 $(1.75 \%)$ patients who continued prescription opioids died of an overdose ${ }^{61}$ LTOT discontinuation was associated with a hazard ratio for overdose death of 2.94 (1.01 to 8.61) after adjusting for age and race. In another retrospective study of 43 VHA patients who stopped opioids due to opioid agreement violations, no patients overdosed. ${ }^{57} \mathrm{~A}$ limitation of these 3 studies examining overdose is that they were not designed to evaluate causation (i.e., whether opioid overdoses occurred because patients had uncontrolled pain and sought illicit opioids when their prescription doses stopped or whether they had underlying opioid use disorder that was unmasked or worsened with a taper).

The best evidence on the association between opioid dose reduction and suicidal ideation and suicidal self-directed violence is a retrospective study of 509 VHA patients who underwent clinician-initiated tapers due mostly (75\%) to aberrant behaviors. In this study, 47 (9.2\%) patients had newonset suicidal ideation and 12 patients $(2.4 \%)$ had suicidal self-directed violence in the year following opioid discontinuation. ${ }^{56}$ Baseline PTSD (OR $=2.56,95 \%$ CI 1.23 to 5.32) and psychotic disorders $(\mathrm{OR}=3.19,95 \%$ CI 1.14 to 8.89$)$ were associated with suicidal ideation and suicidal selfdirection violence, while other co-morbidities including substance use disorder and baseline MEDD were not. An important limitation of this study is that it excluded patients who had no VHA contact or who died in the year following opioid discontinuation, and therefore likely underestimates the actual proportion of patients who experienced suicidal ideation and suicidal self-directed violence.

\section{Retention in Primary Care or Usual Source of Healthcare}

The association between opioid dose reduction or discontinuation and retention in primary care or patients' usual source of healthcare is unclear. The best evidence is a retrospective study of 1,624 patients on LTOT in an academic healthcare system in the Bronx, NY, which found that 78 of 207 patients who tapered opioids ( $4.8 \%$ of the total sample) terminated their care in the year following the taper (defined as no outpatient encounters in the healthcare system). ${ }^{62}$ In this study, opioid taper was significantly associated with termination of care (AOR 4.3, 95\% CI 2.2 to 8.5 ) compared to continuing opioids. 
Evidence on serious harms as well as the other outcomes that we examined in our full report including quality of life, resolution of opioid-related side effects, withdrawal symptoms, and patient satisfaction is unclear (very low quality per GRADE). Findings for these outcomes were supported by only a single or few observational studies with methodological weaknesses including lack of control groups and small sample sizes. Future studies of higher methodologic quality may have different findings for these outcomes.

\section{DISCUSSION}

Many clinicians are reevaluating their approach to LTOT for chronic pain in response to the evolving opioid crisis and calls from organizations such as the CDC to limit the use of highdose opioids. In a pendulum swing from a decade ago, clinical practice norms and quality metrics now favor opioid dose reduction and discontinuation. ${ }^{67}$ While the intent of opioid dose reduction is to prevent opioid-related harms, the net balance of benefits and harms of tapering opioids among patients who have been prescribed LTOT for chronic pain is unclear. It is encouraging that pain severity and pain-related function may improve with more intensive tapering cointerventions and remain unchanged (i.e., not worsen) with less intensive interventions. Although compared to Frank et al. we have slightly more confidence in the findings for pain severity and pain-related function (low versus very low quality per GRADE) among our focused evidence synthesis of studies with the most relevance to VHA populations and settings, additional evidence is needed to have more confidence in these findings.

Perhaps most importantly, despite our inclusion of 14 new studies published since the 2017 review by Frank et al., we found that evidence regarding patient outcomes following tapers remains unclear for serious harms including substance use, opioid overdose, and suicide. Studies that have evaluated these harms are observational and do not establish causation between opioid tapers and serious harms yet support anecdotal reports that LTOT discontinuation can be associated with adverse events and should be further studied. An important discrepancy between the CDC, VA/DoD, and other guidelines and real-world practice is that opioid discontinuation is often occurring abruptly without shared decision-making as guidelines recommend and without linking patients to additional supports including treatment for opioid use disorder. This discrepancy further adds to the complexity of studying opioid tapering outcomes, as not only do we have low and very-low quality evidence regarding outcomes of LTOT tapers when implemented with shared decision-making and multimodal supports, we also have very-low quality evidence regarding outcomes when opioid discontinuation occurs rapidly and without patient buy-in.

These findings underscore the importance of individualized shared decision-making with patients regarding LTOT tapers and suggest that patients should be offered pain management supports when possible. The recent editorial by authors of the CDC guideline, "No Shortcuts to Safer Opioid Prescribing," is aptly titled. In the face of inadequate evidence regarding the overall balance of benefits and harms of LTOT tapers, frontline clinicians should take time to engage patients in conversations about lowering opioid doses and this time should be protected by health system leaders and payers. Close monitoring of patients during and after LTOT tapers is warranted given the potential for harms including overdose and suicide, which have not been sufficiently studied. Given observational findings that VHA patients with PTSD and psychotic disorders may be at higher risk of suicidal ideation and suicidal selfdirected violence following LTOT tapers, clinicians should approach opioid tapers with caution in these populations.

The evidence base included in this review has several important limitations. Many studies were uncontrolled, and therefore potentially subject to bias due to unmeasured confounders. Most studies were small and conducted in a single center, limiting their power and generalizability to other practice settings. Similarly, several studies were of patients with very high baseline MEDD (> $200 \mathrm{mg}$ ). At this stage of the opioid crisis, fewer patients may be prescribed high-dose opioids overall, and therefore results from studies of patients on higher doses may have limited applicability. Other changes in opioid prescribing practices (eg, short-acting vs long-acting or less use of specific opioids such as methadone) may also limit the applicability of studies to current practice. Length of follow-up was also too short $(<1$ year in most studies) to evaluate the durability of treatment outcomes. Improved understanding of the impact of taper interventions over time, including longer-term impacts on pain and function and potential harms, as well as the percentage of patients who restart or increase opioids, would help inform clinical decisionmaking.

In terms of our review methods, limitations include our literature search start date of January 1, 2017 (the end search date of the Frank et al. review) and the possibility that we did not identify relevant studies published before that date, our use of 2 nd reviewer checking in lieu of dual independent review, and our scope that focused on studies directly evaluating opioid tapers and not other chronic pain interventions that also may have led to reduced opioid doses. However, considering that our findings are similar to those in the systematic review by Frank et al., it is unlikely that changes in our review processes would have led to important changes in our conclusions.

Future studies of opioid tapering interventions should provide enough context regarding patient chronic pain and LTOT histories and tapering reasons (i.e., patient preference, persistent pain despite opioids, opioid side effects, or concern for misuse) to allow clinicians and other stakeholders to interpret study results and determine whether the results apply to a given patient or patient population. Two distinct patient groups with potentially different risks for LTOT tapering 
harms should be evaluated - those who voluntarily engage in a tapering plan and those who are tapering due to clinician concerns for LTOT safety and/or opioid misuse. An informative study intervention would include a taper aimed at reducing MEDD below a specified threshold and examine a broad range of outcomes including the proportion of patients with clinically important rebound pain and adverse events such as new or increased substance use, overdose, and suicide for which more evidence is urgently needed.

Acknowledgments: The authors gratefully acknowledge Mark Helfand, MD, MPH, MS, for methodological and clinical input; Joseph Frank, MD, MPH, and Friedhelm Sandbrink, MD, for input on scope; and Payten Sonnen, BA, for editorial support.

Corresponding Author: Katherine Mackey, MD, MPP; Evidence Synthesis Program (ESP) Coordinating Center, VA Portland Health Care System, R\&D 713710 SW U.S. Veterans Hospital Road, Portland, OR, USA (e-mail: katherine.mackey@va.gov).

Funding This material is based upon work supported by the Department of Veterans Affairs, Veterans Health Administration, Office of Research and Development, Quality Enhancement Research Initiative (QUERI), Evidence Synthesis Program (ESP).

\section{Compliance with Ethical Standards:}

Conflict of Interest: The authors declare that they do not have a conflict of interest.

Disclaimer: The views expressed in this article are those of the authors and do not necessarily represent the views of the Department of Veterans Affairs or the US government.

\section{REFERENCES}

1. Centers for Disease Control and Prevention. Opioid Overdose: Understanding the Epidemic. https://www.cdc.gov/drugoverdose/epidemic/ index.html. Published 2018. Accessed Jun, 2019

2. Guy G, Zhang $\mathbf{K}$, Bohm M, et al. Vital Signs: Changes in Opioid Prescribing in the United States, 2006-2015. Morbid Mortal Wkly Rep 2017;66(26):697-704

3. Oregon Pain Guidance. Tapering - guidance and tools. https://www. oregonpainguidance.org/guideline/tapering/. Published 2018. Accessed Aug, 2019.

4. American Academy of Family Physicians. Tapering Resource. https:// www.aafp.org/dam/AAFP/documents/patient_care/pain_management/ tapering-resource.pdf. Accessed Aug, 2019.

5. Washington State Agency Medical Directors' Group. Interagency guideline on prescribing opioids for pain. http://www.agencymeddirectors.wa. gov/Files/2015AMDGOpioidGuideline.pdf. Published 2015. Accessed Aug, 2019.

6. Department of Veterans Affairs, Department of Defense. VA/DoD Clinical Practice Guideline for Opioid Therapy for Chronic Pain. https://www. healthquality.va.gov/guidelines/Pain/cot/VADoDOTCPG022717.pdf. Published 2017. Accessed.

7. Bohnert A, Logan J, Ganoczy D, Dowell D. A detailed exploration into the association of prescribed opioid dosage and overdose deathes among patients with chornic pain. Med Care 2016;54(5):435-441.

8. Frank JW, Lovejoy TI, Becker WC, et al. Patient outcomes in dose reduction or discontinuation of long-term opioid therapy: a systematic review. Ann Intern Med 2017;167(3):181-191.

9. Throckmorton D. Statement by Douglas Throckmorton, MD, Deputy Center Director for Regulatory Programs in FDA's Center for Drug Evaluation and Research, on new Opioid Analgesic Labeling Changes. https://www.fda.gov/news-events/press-announcements/statement- douglas-throckmorton-md-deputy-center-director-regulatory-programsfdas-center-drug-0. Published 2019. Accessed Jul, 2019.

10. Dowell D, Haegerich T, Chou R. No Shortcuts to Safer Opioid Prescribing. N Engl J Med 2019.

11. Mackey K, Anderson J, Bourne D, Chen E, Peterson K. Evidence Brief: Benefits and Harms of Long-term Opioid Dose Reduction or Discontinuation in Patients with Chronic Pain. Washington, DC: Evidence Synthesis Program, Health Services Research and Development Service, Office of Research and Development, Department of Veterans Affairs VA ESP Project \#09-199. 2019. https://www.hsrd.research.va.gov/publications/esp/reports.cfm.

12. Moher D, Liberati A, Tetzlaff J, Altman DG. Preferred reporting items for systematic reviews and meta-analyses: the PRISMA statement. BMJ (Clinical Research Ed). 2009;339:b2535.

13. Methods Guide for Effectiveness and Comparative Effectiveness Reviews. AHRQ Publication No. 10(14)-EHC063-EF. In. Rockville, MD: Agency for Healthcare Research and Quality; January 2014:Chapters available at: www.effectivehealthcare.ahrq.gov.

14. Sterne JA, Hernan MA, Reeves BC, et al. ROBINS-I: a tool for assessing risk of bias in non-randomised studies of interventions. Bmj. 2016;355:i4919.

15. Grading of Recommendations Assessment Development and Evaluation. Grade Working Group. https://www.gradeworkinggroup.org/. Published 2019. Accessed Jan, 2020.

16. Blondell RD, Ashrafioun L, Dambra CM, Foschio EM, Zielinski AL, Salcedo DM. A clinical trial comparing tapering doses of buprenorphine with steady doses for chronic pain and co-existent opioid addiction. J Addict Med 2010;4(3):140-146.

17. Cowan DT, Wilson-Barnett J, Griffiths P, Vaughan DJ, Gondhia A, Allan LG. A randomized, double-blind, placebo-controlled, cross-over pilot study to assess the effects of long-term opioid drug consumption and subsequent abstinence in chronic noncancer pain patients receiving controlled-release morphine. Pain Med 2005;6(2):113-121.

18. Sullivan MD, Turner JA, DiLodovico C, D'Appollonio A, Stephens K, Chan Y-F. Prescription opioid taper support for outpatients with chronic pain: A randomized controlled trial. J Pain 2017; 18(3):308-318.

19. Webster L, Harper J, Stambler N, Israel R. Analysis of impact of oral methylnaltrexone for opioid-induced constipation (OIC) on opioid analgesia and withdrawal symptoms in patients with chronic noncancer pain (CNCP) taking methadone. Pain Med (United States). 2017; 18 (3):620.

20. Schwarzer A, Aichinger-Hinterhofer M, Maier C, Vollert J, Walther JW. Sleep-disordered breathing decreases after opioid withdrawal: results of a prospective controlled trial. Pain. 2015;156(11):2167-2174.

21. Baron MJ, McDonald PW. Significant pain reduction in chronic pain patients after detoxification from high-dose opioids. J Opioid Manag 2006;2(5):277-282.

22. Berland DW, Malinoff HL, Weiner MA, Przybylski R. When opioids fail in chronic pain management: the role for buprenorphine and hospitalization. Am J Ther 2013;20(4):316-321.

23. Crisostomo RA, Schmidt JE, Hooten WM, Kerkvliet JL, Townsend CO, Bruce BK. Withdrawal of analgesic medication for chronic low-back pain patients: improvement in outcomes of multidisciplinary rehabilitation regardless of surgical history. Am J Phys Med Rehabil 2008;87(7):527-536.

24. Cunningham JL, Evans MM, King SM, Gehin JM, Loukianova LL Opioid tapering in fibromyalgia patients: experience from an interdisciplinary pain rehabilitation program. Pain Med 2016;17(9):1676-1685.

25. Daitch D, Daitch J, Novinson D, Frey M, Mitnick C, Pergolizzi J, Jr. Conversion from high-dose full-opioid agonists to sublingual buprenorphine reduces pain scores and improves quality of life for chronic pain patients. Pain Med 2014;15(12):2087-2094.

26. Daitch J, Frey ME, Silver D, Mitnick C, Daitch D, Pergolizzi J, Jr. Conversion of chronic pain patients from full-opioid agonists to sublingual buprenorphine. Pain Physician. 2012;15(3 Suppl):Es59-66.

27. Darchuk KM, Townsend CO, Rome JD, Bruce BK, Hooten WM. Longitudinal treatment outcomes for geriatric patients with chronic non-cancer pain at an interdisciplinary pain rehabilitation program. Pain Med 2010;11(9):1352-1364.

28. Dersh J, Mayer TG, Gatchel RJ, Polatin PB, Theodore BR, Mayer EA. Prescription opioid dependence is associated with poorer outcomes in disabling spinal disorders. Spine. 2008;33(20):2219-2227.

29. Drossman DA, Morris CB, Edwards H, et al. Diagnosis, characterization, and 3-month outcome after detoxification of 39 patients with narcotic bowel syndrome. Am J Gastroenterol 2012;107(9):1426-1440. 
30. Harden $\mathbf{P}$, Ahmed S, Ang $\mathbf{K}$, Wiedemer $\mathbf{N}$. Clinical implications of tapering chronic opioids in a veteran population. Pain Med 2015; 16(10): 1975-1981.

31. Heiwe S, Lonnquist I, Kallmen $\mathbf{H}$. Potential risk factors associated with risk for drop-out and relapse during and following withdrawal of opioid prescription medication. Eur J Pain 2011;15(9):966-970.

32. Hooten WM, Townsend CO, Bruce BK, Warner DO. The effects of smoking status on opioid tapering among patients with chronic pain. Anesth Analg 2009; 108(1):308-315.

33. Hooten WM, Townsend CO, Sletten CD, Bruce BK, Rome JD. Treatment outcomes after multidisciplinary pain rehabilitation with analgesic medication withdrawal for patients with fibromyalgia. Pain Med 2007;8(1):8-16.

34. Hooten WM, Townsend CO, Decker PA. Gender differences among patients with fibromyalgia undergoing multidisciplinary pain rehabilitation. Pain Med 2007;8(8):624-632.

35. Hooten WM, Warner DO. Varenicline for opioid withdrawal in patients with chronic pain: a randomized, single-blinded, placebo controlled pilot trial. Addict Behav 2015;42:69-72.

36. Huffman KL, Rush TE, Fan Y, et al. Sustained improvements in pain, mood, function and opioid use post interdisciplinary pain rehabilitation in patients weaned from high and low dose chronic opioid therapy. Pain. 2017; 158(7): 1380-1394

37. Kidner CL, Mayer TG, Gatchel RJ. Higher opioid doses predict poorer functional outcome in patients with chronic disabling occupational musculoskeletal disorders. J Bone Joint Surg 2009;91(4):919-927.

38. Krumova EK, Bennemann P, Kindler D, Schwarzer A, Zenz M, Maier C. Low pain intensity after opioid withdrawal as a first step of a comprehensive pain rehabilitation program predicts long-term nonuse of opioids in chronic noncancer pain. Clin J Pain 2013;29(9):760-769.

39. Malinoff HL, Barkin RL, Wilson G. Sublingual buprenorphine is effective in the treatment of chronic pain syndrome. Am J Ther 2005;12(5):379384.

40. Murphy JL, Clark ME, Banou E. Opioid cessation and multidimensional outcomes after interdisciplinary chronic pain treatment. Clin J Pain 2013;29(2):109-117.

41. Nilsen HK, Stiles TC, Landro NI, Fors EA, Kaasa S, Borchgrevink PC. Patients with problematic opioid use can be weaned from codeine without pain escalation. Acta Anaesthesiol Scand 2010;54(5):571-579.

42. Rome JD, Townsend CO, Bruce BK, Sletten CD, Luedtke CA Hodgson JE. Chronic noncancer pain rehabilitation with opioid withdrawal: comparison of treatment outcomes based on opioid use status at admission. Mayo Clin Proc 2004;79(6):759-768.

43. Rosenblum A, Cruciani RA, Strain EC, et al. Sublingual buprenorphine/naloxone for chronic pain in at-risk patients: development and pilot test of a clinical protocol. J Opioid Manag 2012;8(6):369382 .

44. Roux P, Sullivan MA, Cohen J, et al. Buprenorphine/naloxone as a promising therapeutic option for opioid abusing patients with chronic pain: reduction of pain, opioid withdrawal symptoms, and abuse liability of oral oxycodone. Pain. 2013;154(8): 1442-1448.

45. Taylor CB, Zlutnick SI, Corley MJ, Flora J. The effects of detoxification, relaxation, and brief supportive therapy on chronic pain. Pain. 1980;8(3):319-329.

46. Townsend CO, Kerkvliet JL, Bruce BK, et al. A longitudinal study of the efficacy of a comprehensive pain rehabilitation program with opioid withdrawal: comparison of treatment outcomes based on opioid use status at admission. Pain. 2008;140(1):177-189.

47. Wang $\mathbf{H}$, Akbar $\mathbf{M}$, Weinsheimer $\mathbf{N}$, Gantz S, Schiltenwolf $\mathbf{M}$. Longitudinal observation of changes in pain sensitivity during opioid tapering in patients with chronic low-back pain. Pain Med 2011;12(12):1720-1726.
48. Weimer MB, Hartung DM, Ahmed S, Nicolaidis C. A chronic opioid therapy dose reduction policy in primary care. Subst Abus 2016;37(1): 141-147.

49. Younger J, Barelka P, Carroll I, et al. Reduced cold pain tolerance in chronic pain patients following opioid detoxification. Pain Med 2008;9(8):1158-1163.

50. Kurita GP, Hojsted J, Sjogren P. Tapering off long-term opioid therapy in chronic non-cancer pain patients: A randomized clinical trial. Eur J Pain 2018;22(8): 1528-1543.

51. Bienek N, Maier C, Kaisler M, Michel-Lauter B, Schwarzer A, MeyerFriesem CH. Intensity of withdrawal symptoms during opioid taper in patients with chronic pain-individualized or fixed starting dosage? Pain Med 2019;26.

52. Sharp AL, Shen E, Wu YL, et al. Satisfaction with care after reducing opioids for chronic pain. Am J Manag Care 2018;24(6):e196-e199.

53. Thakral M, Walker RL, Saunders $\mathbf{K}$, et al. Impact of opioid dose reduction and risk mitigation initiatives on chronic opioid therapy patients at higher risk for opioid-related adverse outcomes. Pain Med 2018;19(12):2450-2458.

54. Von Korff M, Saunders K, Dublin S, et al. Impact of chronic opioid therapy risk reduction initiatives on opioid overdose. J Pain 2019;20(1): 108-117.

55. Darnall BD, Ziadni MS, Stieg RL, Mackey IG, Kao MC, Flood P. Patientcentered prescription opioid tapering in community outpatients with chronic pain. JAMA Intern Med 2018;178(5):707-708.

56. Demidenko MI, Dobscha SK, Morasco BJ, Meath TH, Ilgen MA, Lovejoy TI. Suicidal ideation and suicidal self-directed violence following clinician-initiated prescription opioid discontinuation among long-term opioid users. Gen Hosp Psychiatry 2017;47:29-35.

57. Hundley L, Spradley S, Donelenko S. Assessment of outcomes following high-dose opioid tapering in a Veterans Healthcare System. J Opioid Manag 2018;14(2):89-101.

58. McPherson S, Lederhos Smith C, Dobscha SK, et al. Changes in pain intensity after discontinuation of long-term opioid therapy for chronic noncancer pain. Pain. 2018;159(10):2097-2104.

59. Mark T, Parish W. Opioid medication discontinuation and risk of adverse opioid-related health care events. J Subst Abus Treat 2019.

60. DiBenedetto DJ, Wawrzyniak KM, Finkelman M, et al. Relationships Between Opioid Dosing, Pain Severity, and Disability in a CommunityBased Chronic Pain Population: An Exploratory Retrospective Analysis. Pain Med 2019;17:17.

61. James JR, Scott JM, Klein JW, et al. Mortality After Discontinuation of Primary Care-Based Chronic Opioid Therapy for Pain: a Retrospective Cohort Study. J Gen Intern Med 2019;34(12):2749-2755.

62. Perez HR, Buonora M, Cunningham CO, Heo M, Starrels JL. Opioid Taper Is Associated with Subsequent Termination of Care: a Retrospective Cohort Study. J Gen Intern Med 2019;19:19.

63. Nicholas MK, Asghari A, Sharpe L, et al. Reducing the use of opioids by patients with chronic pain: an effectiveness study with long-term followup. Pain. 2019;19:19.

64. Wang DY, Salem JE, Cohen JV, et al. Fatal Toxic Effects Associated With Immune Checkpoint Inhibitors: A Systematic Review and Meta-analysis. JAMA Oncol 2018;4(12):1721-1728.

65. Townsend MJ, Kelly L, Ogur B. A group program for chronic pain patients on chronic opioids. J Gen Intern Med 2018;33(2 Suppl 1):758759

66. Murphy GSJ. Methadone provides a preventive analgesic effect in patients undergoing cardiac surgery. Anaesth Intensive Care.47(2):6-7.

67. Kertesz SG. Outcomes after opioid dose reductions and stoppage: It's time to start counting. J Subst Abus Treat 2019;103:64-65.

Publisher's Note Springer Nature remains neutral with regard to jurisdictional claims in published maps and institutional affiliations. 